\title{
Fabrication and characterization of $S$. cilliare fibre reinforced polymer composites
}

\author{
A S SINGHA* and VIJAY KUMAR THAKUR \\ Department of Chemistry, National Institute of Technology, Hamirpur 177 005, India
}

MS received 16 March 2008

\begin{abstract}
In the recent times, there has been an ever-increasing interest in green composite materials for its applications in the field of industries, aerospace, sports, household etc and in many other fields. In this paper, fabrication of Saccharum cilliare fibre reinforced green polymer composites using resorcinol formaldehyde (RF) as a novel matrix has been reported. A systematic approach for processing of polymer is presented. Effect of fibre loading on mechanical properties like flexural, tensile, compressive and wear resistances has also been determined. Reinforcing of the RF resin with Saccharum cilliare (SC) fibre was done in the form of particle size (200 micron). Present work reveals that mechanical properties of the RF resin have been found to increase up to $\mathbf{3 0} \%$ fibre loading and then decreases. Morphological and thermal studies of the resin, fibre and particle reinforced (P-Rnf) green composites have also been studied.
\end{abstract}

Keywords. Composites; reinforcements; optimization; mechanical properties.

\section{Introduction}

Over the past few decades, polymers have replaced many of the conventional materials in a variety of applications. This is possible because of the advantages polymers offer over conventional materials. Ease of processing, productivity, and decrease in cost of the materials are the most important advantages of using polymers in a number of fields. Emerging community concerns and a growing environmental awareness throughout the world has forced the researchers to synthesize new green materials and processes that enhance the environmental quality of products (Chauhan et al 2000a,b; Bhatnagar and Sain 2005; Singha et al 2008a,b). In most of its applications, the properties of polymers are modified using natural fillers and natural fibres to suit the high strength/high modulus requirements (Bledzki et al 1996, 1998; Bledzki and Gasson 1999; Chauhan et al 1999, 2001; Singha et al 2002). Keeping in view the eco-friendly advantages of green materials a large number of industries throughout the world are initiating the design and engineering of these products. Sustainable growth and eco-efficiency are of most importance to the majority of industries. At present greater attention is being given for the production of green composites which can help in resolving future environmental problems (Gatenholm et al 1993; Gassan and Bledzki 1997; De and Adhikari 2004). In this perspective easy availability, biodegradability, eco-friendliness, light weight

*Author for correspondence (assingha@gmail.com) etc have become important considerations in the fabrication of new products (Hagstrand and Oksman 2001; Kaith et al 2005, 2007; Singha and Shama 2007a). At present various workers are focusing their attention on use of natural fibres in place of synthetic fibres in various fields especially as reinforcing fillers (Nabi Saheb and Jog 1999; Nakagiato and Yano 2004; Singha et al 2005; Panthapulakkal et al 2006; Kaith et al 2008). Natural fibre reinforced polymer composites have recently been preferred over composites prepared with ceramic and metal matrix because of their better properties. Natural fibrereinforced polymers offer advantages over other conventional materials when specific properties are compared. These composites are finding applications in diverse fields from appliances to spacecrafts. The use of natural fibres derived from a number of renewable resources as reinforcing fibres in both thermoplastic and thermoset matrix composites provides positive environmental benefits and offer numerous advantages over conventional materials including lightness, resistance to corrosion, abrasion and ease of processing etc (Gassan and Bledzki 1997; Velde van de and Kiekens 2001, 2003; Kaith et al 2008). Natural fibres like flax, jute, pinus, Saccharum cilliare oil palm have all been proved to be good reinforcements in thermoset and thermoplastic matrices. Saccharum cilliare fibre is abundantly found in Himachal Pradesh. The literature survey has revealed that no work has been done on utilization of this fibre as reinforcing material in the polymer composites (Singha et al 2008a, b). Keeping in view the easy availability and many other ecofriendly advantages, we have used this fibre as reinforcing mate- 
rial for the preparation of resorcinol-formaldehyde (R-F) resin based green composites. The green composites so prepared were subjected to evaluation of their mechanical, morphological and thermal properties.

\section{Experimental}

\subsection{Materials}

Resorcinol and formaldehyde solutions were supplied by Qualigens Chemicals Ltd and were used as received. Resorcinol-formaldehyde (R-F) was used as a matrix polymer. The natural fibrous materials used as the reinforcing filler in the composite were Saccharum cilliare fibres of particle dimensions $(200 \mu \mathrm{m})$. Weights of the samples were taken on Shimadzu make electronic balance (LIBROR AEG-220), curing of samples was done on compression molding machine (SANTECH INDIA Ltd), thermal studies were carried out on thermal analyser (Perkin Elmer) and SEM micrographs were taken on LEO $435 \mathrm{VP}$

\subsection{Synthesis of resorcinol-formaldehyde resin}

Resorcinol-formaldehyde (RF) resin was synthesized by the standard method developed in our Applied Chemistry, Research Laboratory (Singha and Thakur 2007b). Resorcinol and formaldehyde were taken in different molar ratios $(1 \cdot 0: 1 \cdot 0,1.0: 1.5,1 \cdot 0: 2 \cdot 0,1 \cdot 0: 1.5$ and $1.0: 3.0)$ by weight, in a reaction kettle and were mixed with the help of a mechanical stirrer. Since the reaction is exothermic, proper care was taken to maintain the temperature between 40 and $45^{\circ} \mathrm{C}$, for initial $1 \mathrm{~h}$. Then temperature was increased to $50^{\circ} \mathrm{C}$ and the mixture was heated at this temperature, till complete resinification. Then heating was stopped and the resin was cooled. The resin synthesized was then transferred to a specially made mould. Resin sheets of size $150 \times 150 \times 5.0 \mathrm{~mm}$ were prepared by a closed mould method as described somewhere else (Singha et al 2005). The mould was then closed and kept under pressure (4.0 MPa) until the resin was set into a hard mass. All the specimens were post cured at $55^{\circ} \mathrm{C}$ for $5 \mathrm{~h}$.

\subsection{Synthesis of polymer biocomposites}

Saccharum cilliare fibres collected were first thoroughly washed with detergent powder. After this these were soaked in hot distilled water for $3 \mathrm{~h}$, dried for $48 \mathrm{~h}$ in air at room temperature followed by drying at $100^{\circ} \mathrm{C}$ for $24 \mathrm{~h}$ to adjust it to a moisture content of $1-2 \%$ and then stored over desiccant in sealed container. The dried Saccharum cilliare fibres were grinded to a powder of pore size $200 \mu \mathrm{m}$. Thorough mixing of Saccharum cilliare fibre particles with resorcinol-formaldehyde resin was done using mechanical stirrer with different loadings $(10,20$,
30 and $40 \%$ ) in terms of weight. The surfaces of molds to be used were coated on the inside with oleic acid to avoid adhesion of the mixture and to allow easy removal of the composites. The above mixture was poured into a specially made mold. The mixture was then spread equally on the surface of the mold. Composite sheets of size $150 \times 150 \times 5.0 \mathrm{~mm}$ were prepared by compression molding technique on a Compression Molding Machine. Compression molding was performed in a hot press using a mold preheated to $50^{\circ} \mathrm{C}$. The material first placed in a hot open mold was left for about $5 \mathrm{~min}$, and then the mold was closed. Composite sheets were prepared by hot pressing the mold at $50^{\circ} \mathrm{C}$ for $30 \mathrm{~min}$. The pressure applied ranges from 3-4 MPa depending on the loading of reinforcing material. All the specimens were then post cured at $50^{\circ} \mathrm{C}$ for $12 \mathrm{~h}$.

\subsection{Mechanical testing}

Tensile, compressive, flexural and wear tests were performed on specimens cut from the above prepared composite material. Seven specimens of each sample were used for the determination of mechanical properties and the tests were conducted at ambient laboratory environment. Testing of samples for tensile, compressive and flexural strengths were done on Computerized Universal Testing Machine (HOUNSFIELD H25KS), wear testing was done on Wear \& Friction Monitor (DUCOM-TR-20L).

\subsection{Analysis of mechanical properties of samples}

The tensile strength test was conducted on Computerized Universal Testing Machine (HOUNSFIELD H25KS). The specimens of dimension $100 \times 10 \times 5 \mathrm{~mm}$ were used for analysis. The tensile test was conducted in accordance with ASTM D 3039 method. The test was conducted at a constant strain rate of $10 \mathrm{~mm} / \mathrm{min}$. Force was applied till the failure of the sample and load-elongation curve was obtained. The compression test was conducted in accordance with ASTM D 3410 method. Composite sample was held between the two platforms and the strain rate was fixed at $10 \mathrm{~mm} / \mathrm{min}$ whereas the total compression range was $7.5 \mathrm{~mm}$. The compression stress was applied till the failure of sample. Flexural strength of samples was also tested on Computerized Universal Testing Machine. The three-point bend flexural test was conducted in accordance with ASTM D 790 method. The wear test of the sample was conducted on Wear \& Friction Monitor (DUCOM-TR-20L). Wear resistance of composites was carried out as per ASTM D 3702 method.

\subsection{SEM analysis of samples}

In order to evaluate changes in the composite surface morphology, fibres and matrix were analysed by scanning 
electron microscopy (SEM). The excitation energy used was $5 \mathrm{keV}$. To achieve good electric conductivity all samples were first carbon sputtered followed by sputtering a gold palladium mixture before examination. SEM micrographs of the samples show the morphology of the polymer composites prepared. These micrographs clearly show the difference between unloaded and loaded RF matrix.

\subsection{Thermal analysis of samples}

Thermal analysis of natural and synthetic polymers gives us good account of thermal stability of materials. Thermogravimetric analysis (TGA) and differential thermal analysis (DTA) studies of samples were carried out in nitrogen atmosphere on a thermal analyser (Perkin Elmer) at a heating rate of $10^{\circ} \mathrm{C} / \mathrm{min}$. TGA is used to characterize the decomposition and thermal stability of materials under a variety of conditions, and to examine the kinetics of the physico-chemical processes occurring in the sample. Basically in this method a change in thermal stability is examined in terms of percentage weight loss as a function of temperature. The mass change characteristics of a material are strongly dependent on the experimental conditions such as sample mass, volume and physical form, the shape and nature of the sample holder, the nature and pressure of the atmosphere in the sample chamber and the scanning rate and all have important influences on the characteristics of the recorded TG curve. At the same time DTA involves comparing the precise temperature difference between a sample and an inert reference material, while heating both.

\section{Results and discussion}

In the study of the behaviour of polymer composites, mechanical analysis is a tool of chief importance. It has been proved to be an efficient method to study the behaviour of the materials under different conditions of tension, compression, stress-strain and its role in determining the mechanical properties. Generally mechanical properties of fibre reinforced composites depend on the nature of the matrix material, the distribution and orientation of the reinforcing material and the content of the fibre loading.

\subsection{Mechanism of synthesis of resorcinol- formaldehyde resin}

Resorcinol is a very reactive compound and readily combines with formaldehyde to form methylene derivative (Pizzi and Cameron 1989). In this reaction methylol group occupies either the position ortho to both hydroxyl groups or ortho to one and para to other as shown in scheme 1 . The reaction is carried out in neutral medium as resorcinol is very reactive towards formaldehyde.
Reaction between formaldehyde and resorcinol proceeds vigorously towards thermosetting state when these are heated together. Hence proper care must be taken while carrying out the reaction. Methylolated resorcinols condense with formaldehyde molecules and other resorcinol molecules to form polymeric structure as shown in scheme 2 . In these reactions resorcinol nuclei are joined together through methylene bridges to give complex molecule. Complete methylene bridging is shown in scheme 3.

\subsection{Optimization of resorcinol-formaldehyde resin}

Optimization of resorcinol-formaldehyde resin was done by taking the mechanical properties such as tensile strength, compressive strength, flexural strength and wear resistance into consideration.

3.2a Tensile strength: It has been observed that RF samples of ratio $1.0: 1.5$ bear more load at a particular applied load as compared to samples of other ratios (Singha and Thakur 2007b). This ratio $(1 \cdot 0: 1.5)$ could bear a load of $250.8 \mathrm{~N}$ with an extension of $2 \mathrm{~mm}$ (figure 1 ). On the other hand, samples of other ratios bear low loads.

3.2b Compressive strength: It is evident from figure 2 that the samples of ratio $1 \cdot 0: 1.5$ could bear a load of $1370 \mathrm{~N}$ at a compression of $2.17 \mathrm{~mm}$.

3.2c Flexural test: It is evident from figure 3 that the samples of ratio $1.0: 1.5$ could bear a maximum load of $117.8 \mathrm{~N}$ at a deflection of $1.0 \mathrm{~mm}$.

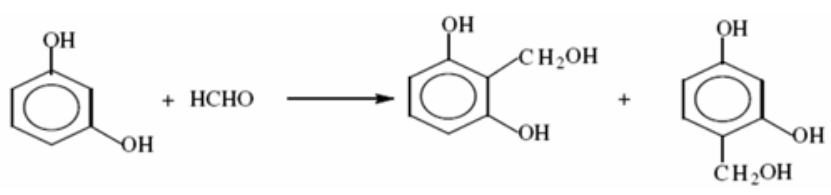

Scheme 1. Formation of methylol derivative

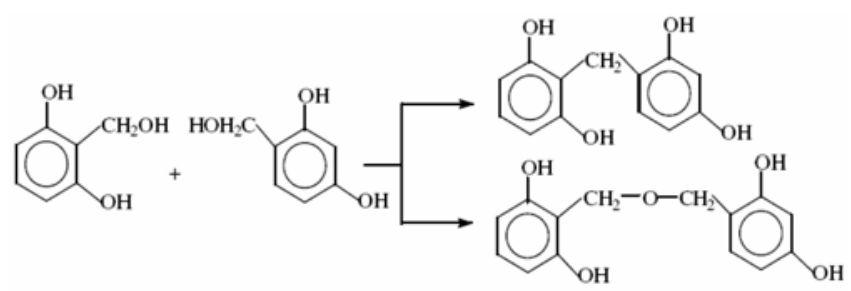

Scheme 2. Condensation reaction of methylated resorcinol to form polymeric structure.

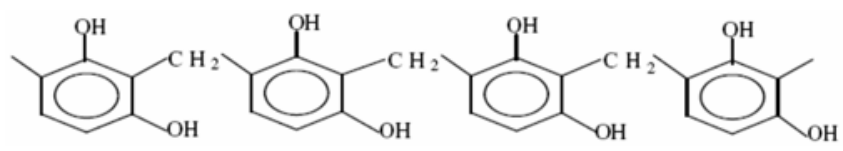

Scheme 3. Methylene bridging in polymerized resorcinol molecules. 
$3.2 \mathrm{~d}$ Wear resistance: It has been observed that wear rate of samples of ratio $1.0: 1.5$ was less as compared to any other samples. Loss of material was due to abrasion and friction of samples with disc (figure 4).

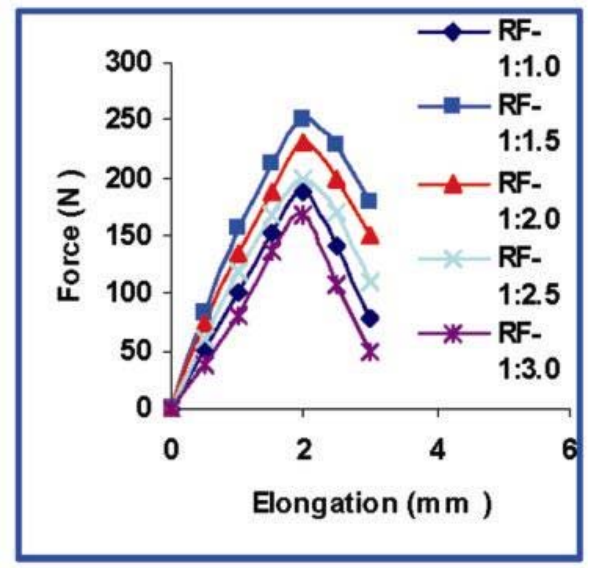

Figure 1. Load-elongation curve of RF resin.

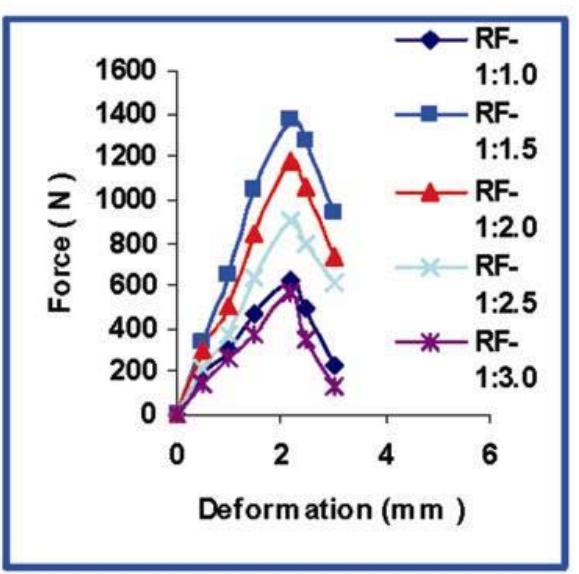

Figure 2. Load-deformation curve of RF resin

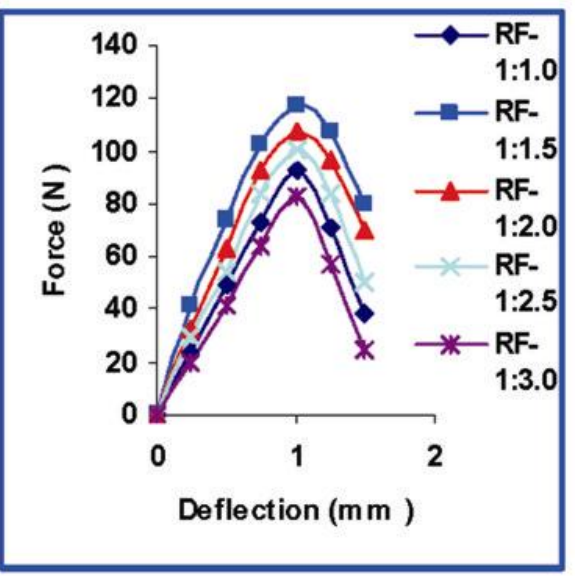

Figure 3. Load-deflection curve of RF resin.
The wear resistance results also support the tensile, compressive and flexural results, as brittle materials have higher wear rate and low tensile, compressive and flexural strength. The ratio $(1.0: 1.5)$ of resorcinol and for-

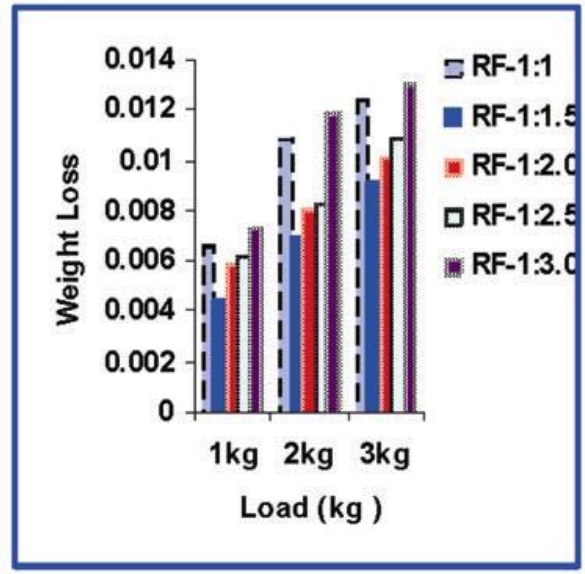

Figure 4. Wear resistance of RF resin.

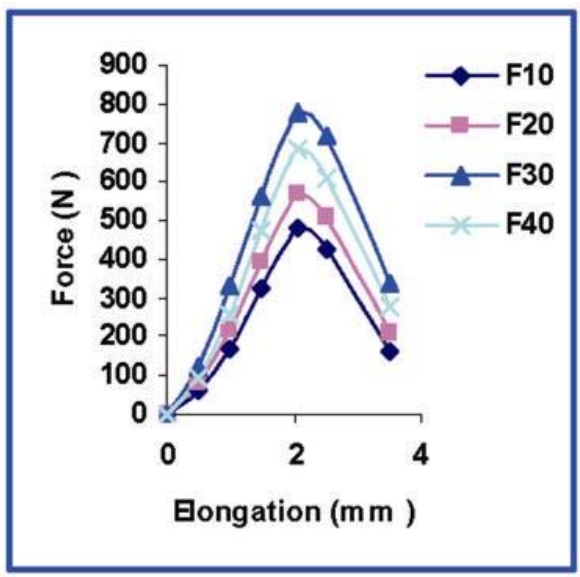

Figure 5. Load-elongation curve of P-Rnf composite with different loadings.

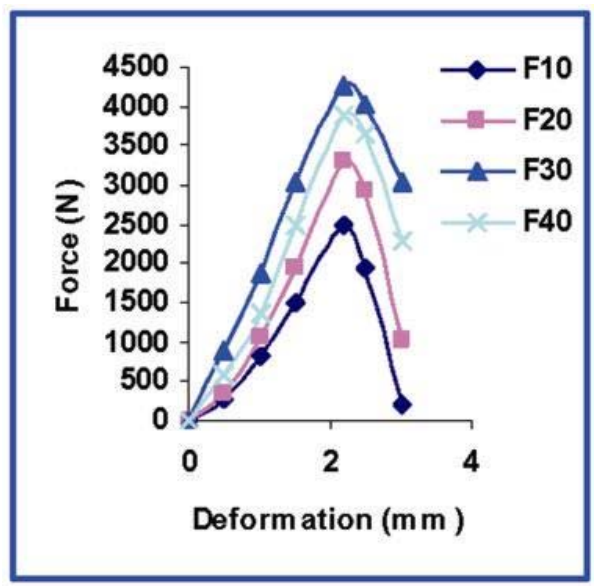

Figure 6. Load-deformation curve of P-Rnf composite with different loadings. 
maldehyde showing optimum mechanical properties was taken for further preparation of biomass reinforced resorcinol-formaldehyde biocomposites.

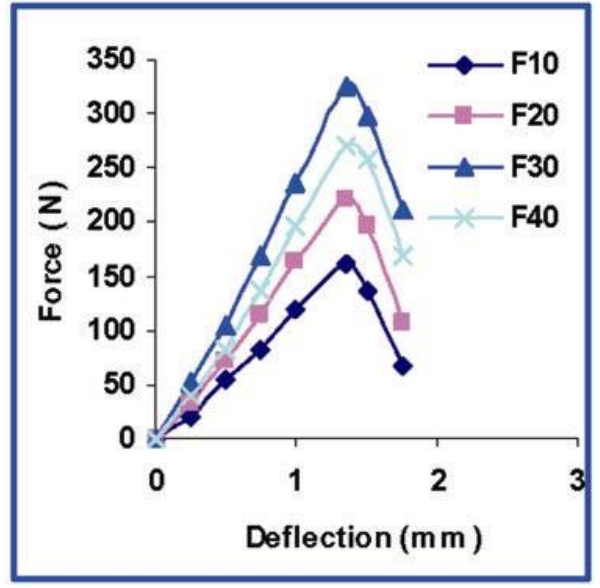

Figure 7. Load-deflection curve of P-Rnf composite with different loadings

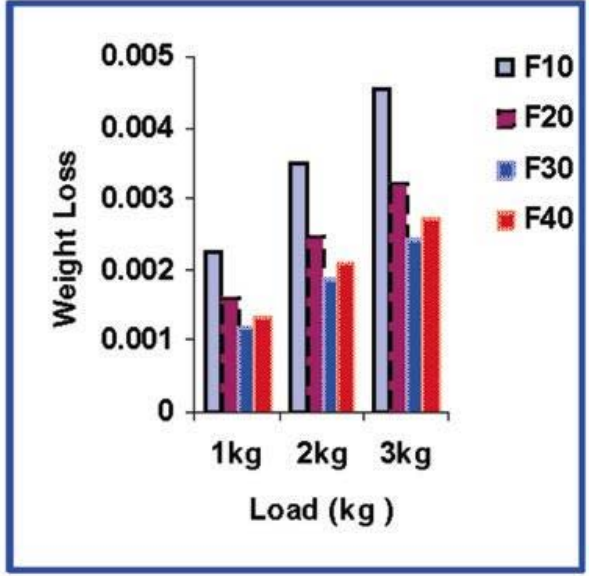

Figure 8. Wear resistance of P-Rnf composite with different loadings.

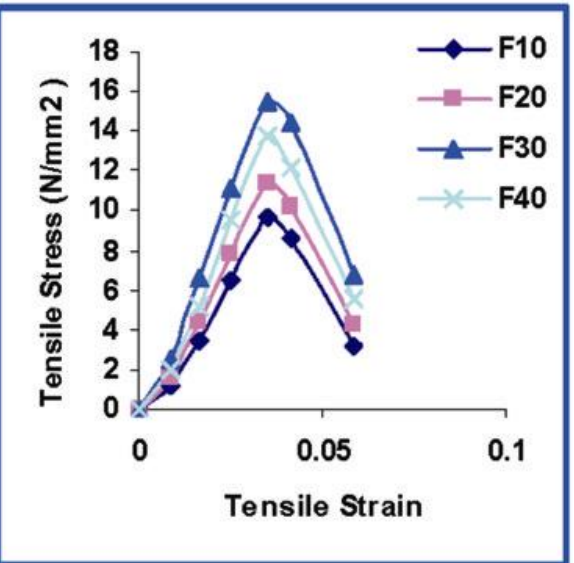

Figure 9. Tensile stress-strain curve of P-Rnf composite.
3.3 Effect of reinforcement on mechanical properties of RF matrix based polymer composites

3.3a Tensile strength: It has been observed that tensile strength of composites increases on reinforcement with Saccharum cilliare fibre. Composites with $30 \%$ wt. loading bear maximum load followed by $40 \%, 20 \%$, and $10 \%$ loadings (figure 5). It has been observed that polymer composite with $30,40,20$ and 10\% loading bear a load of $755.37 \mathrm{~N}, 685.00 \mathrm{~N}, 570.00 \mathrm{~N}$ and $481.58 \mathrm{~N}$, respectively.

3.3b Compressive strength: Compressive strength of $\mathrm{RF}$ matrix has been found to increase as reinforcement with Saccharum cilliare needles. It has been found that on particle reinforcement compressive strength increases to a much more extent. The compressive properties of the composites as a function of load and deformation are presented in figure 6. From the graph it is evident that first compressive force increases with the increase in fibre content but after $30 \%$ fibre content a significant decrease in compressive strength is observed.

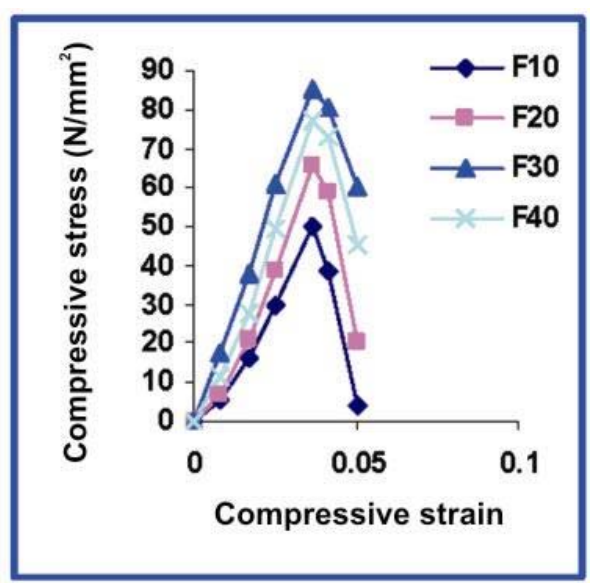

Figure 10. Compressive stress-strain curve of P-Rnf composite.

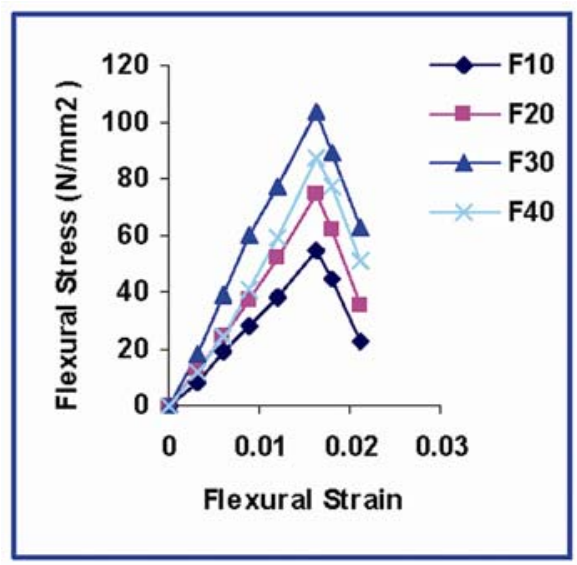

Figure 11. Flexural stress-strain curve of P-Rnf composite 
Table 1. Values of various parameters obtained from tensile stress-strain curve at different loadings.

\begin{tabular}{lccccc}
\hline $\begin{array}{l}\text { Fibre loading } \\
(\text { wt. \%) }\end{array}$ & $\begin{array}{c}\text { Ultimate tensile stress } \\
\left(\mathrm{N} / \mathrm{mm}^{2}\right)\end{array}$ & $\begin{array}{c}\text { Yield strength } \\
\left(\mathrm{N} / \mathrm{mm}^{2}\right)\end{array}$ & $\begin{array}{c}\text { Fracture stress } \\
\left(\mathrm{N} / \mathrm{mm}^{2}\right)\end{array}$ & $\begin{array}{c}\text { Standard } \\
\text { deviation }\end{array}$ & $\begin{array}{c}\text { Tensile modulus } \\
\left(\mathrm{N} / \mathrm{mm}^{2}\right)\end{array}$ \\
\hline $10 \%$ & 9.63 & 8.07 & 9.01 & 1.54 & 251.02 \\
$20 \%$ & 11.40 & 9.08 & 10.74 & 1.75 & 301.70 \\
$30 \%$ & 15.57 & 12.69 & 14.38 & 1.96 & 419.28 \\
$40 \%$ & 13.87 & 11.84 & 12.79 & 2.01 & 387.48 \\
\hline
\end{tabular}

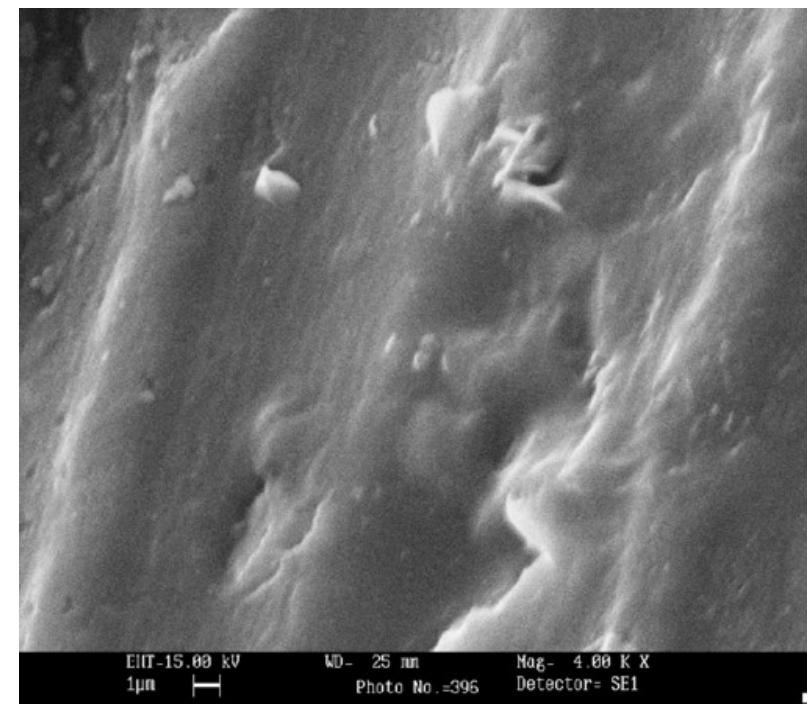

Figure 12. SEM of RF resin.

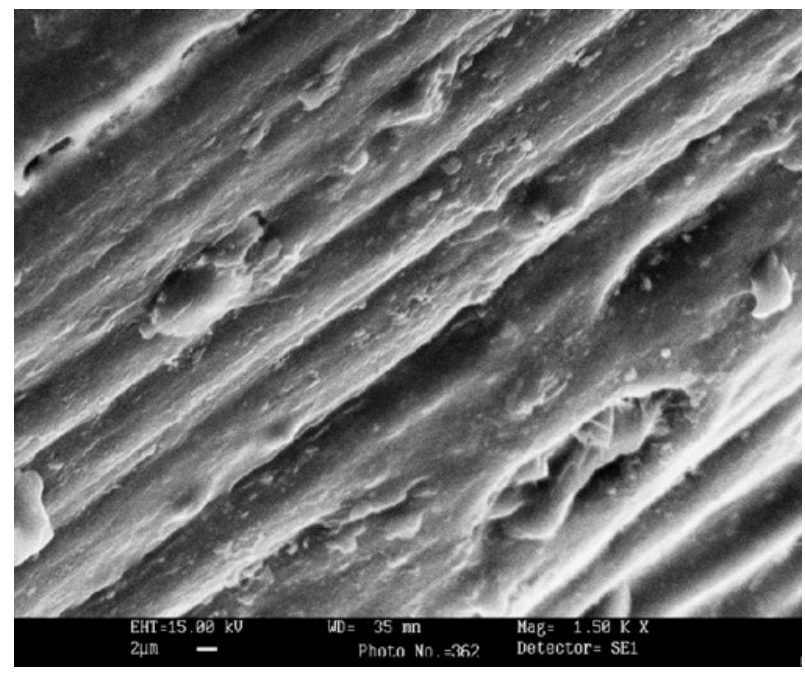

Figure 13. SEM of raw Saccharum cilliare fibre.

It is clear from the figure that composite with 30,40 , 20 and $10 \%$ loading bear a load of $4247.8 \mathrm{~N}, 3860.7 \mathrm{~N}$, 3293.7 and $2496.5 \mathrm{~N}$, respectively.

3.3c Flexural strength: Similar trends as obtained in tensile strength and compressive strength tests have been observed for flexural strength results. The flexural pro- perties of samples as a function of force (in terms of load) and deflection are shown in figure 7. It is clear from the figure that composite with $30,40,20$ and $10 \%$ loading bear a load of $345.32 \mathrm{~N}, 291.00 \mathrm{~N}, 250.00 \mathrm{~N}$ and $181.64 \mathrm{~N}$, respectively.

3.3d Wear test: As evident from figure 8, wear rate of RF matrix decreases appreciably as reinforcement with Saccharum cilliare fibre. It was observed that particle reinforcement decreases the wear rate to a much more extent. Maximum wear resistance behaviour is shown by composite with $30 \%$ loading followed by 40,20 and $10 \%$ loading.

3.3e Stress-strain behaviour: (i) Tensile stress-strain curve: Tensile stress-strain curve is constructed from the load elongation measurements. Tensile stress is obtained on dividing the load by the original area of the cross section of the specimen. The strain used for the compressive stress-strain curve is the average linear strain, which is obtained on dividing the elongation of the gauge length of the specimen, by its original length. Since both stress and strain are obtained by dividing the load and elongation by constant factors, the stress-strain curve has the same shape as the load-elongation curve. The plot of stress vs strain for Saccharum cilliare fibre reinforced polymer composites is shown in figure 9. From the figure it is clear that in the elastic region stress is linearly proportional to strain. When the load exceeds a value corresponding to the yield strength, the specimen undergoes gross plastic deformation. It is permanently deformed if the load is released to zero. Different parameters derived from the tensile stress-strain curve are shown in table 1 .

(ii) Compressive stress-strain curve: Compressive stress-strain curve is constructed from the load deformation measurements. Compressive stress is obtained on dividing the load by the original area of the cross section of the specimen. The strain used for the compressive stress-strain curve is the average linear strain, which is obtained on dividing the deformation of the gauge length of the specimen, by its original length. The compressive stress-strain curve has the same shape as the load-deformation curve. The plot of compressive stress vs strain for Saccharum cilliare fibre reinforced 
Table 2. Values of various parameters obtained from compressive stress-strain curve at different loadings.

\begin{tabular}{lccccc}
\hline $\begin{array}{l}\text { Fibre loading } \\
\text { (wt. \%) }\end{array}$ & $\begin{array}{c}\text { Ultimate compressive } \\
\text { stress }\left(\mathrm{N} / \mathrm{mm}^{2}\right)\end{array}$ & $\begin{array}{c}\text { Yield strength } \\
\left(\mathrm{N} / \mathrm{mm}^{2}\right)\end{array}$ & $\begin{array}{c}\text { Fracture stress } \\
\left(\mathrm{N} / \mathrm{mm}^{2}\right)\end{array}$ & $\begin{array}{c}\text { Standard } \\
\text { deviation }\end{array}$ & $\begin{array}{c}\text { Compressive } \\
\text { modulus }\left(\mathrm{N} / \mathrm{mm}^{2}\right)\end{array}$ \\
\hline $10 \%$ & 49.93 & $40 \cdot 66$ & $46 \cdot 7$ & 1.95 & $1323 \cdot 70$ \\
$20 \%$ & $65 \cdot 87$ & $55 \cdot 42$ & $61 \cdot 78$ & 1.99 & $1757 \cdot 00$ \\
$30 \%$ & 84.94 & $72 \cdot 26$ & 77.37 & $2 \cdot 15$ & $2277 \cdot 00$ \\
$40 \%$ & 77.20 & $66 \cdot 36$ & 73.42 & $2 \cdot 31$ & $2069 \cdot 00$ \\
\hline
\end{tabular}

Table 3. Values of various parameters from flexural stress-strain curve for different percentage of loading.

\begin{tabular}{lccccc}
\hline $\begin{array}{l}\text { Fibre loading } \\
(\text { wt. \%) }\end{array}$ & $\begin{array}{c}\text { Ultimate flexural stress } \\
\left(\mathrm{N} / \mathrm{mm}^{2}\right)\end{array}$ & $\begin{array}{c}\text { Yield strength } \\
\left(\mathrm{N} / \mathrm{mm}^{2}\right)\end{array}$ & $\begin{array}{c}\text { Fracture stress } \\
\left(\mathrm{N} / \mathrm{mm}^{2}\right)\end{array}$ & $\begin{array}{c}\text { Standard } \\
\text { deviation }\end{array}$ & $\begin{array}{c}\text { Flexural modulus } \\
\left(\mathrm{N} / \mathrm{mm}^{2}\right)\end{array}$ \\
\hline $10 \%$ & 54.49 & 41.56 & 48.47 & 1.47 & 3338.97 \\
$20 \%$ & 75.00 & 63.14 & 69.02 & 1.83 & 4044.11 \\
$30 \%$ & 103.59 & 94.73 & 99.85 & 1.94 & 5979.77 \\
$40 \%$ & 87.30 & 79.07 & 84.97 & 1.89 & 4981.61 \\
\hline
\end{tabular}

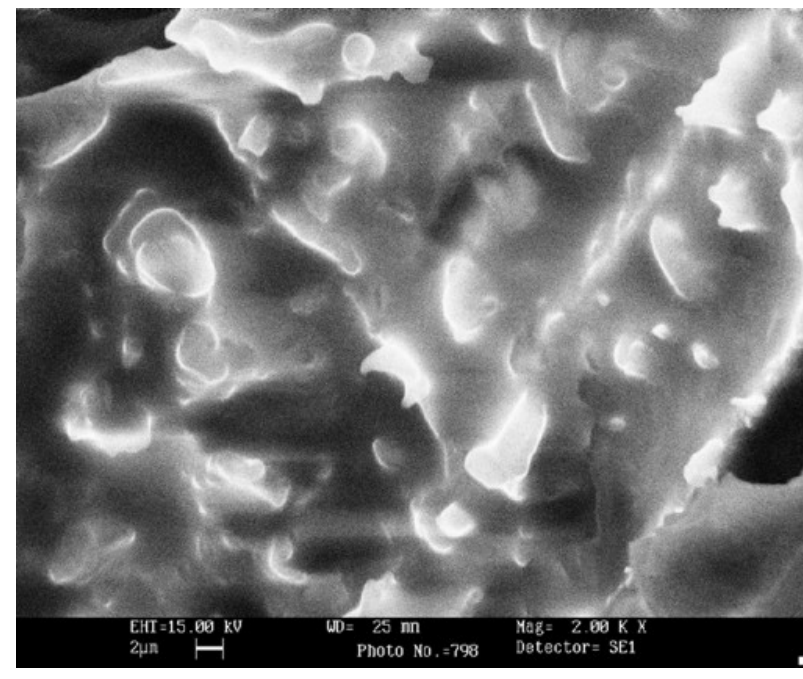

Figure 14. SEM of composite with $10 \%$ fibre loading.

polymer composites is shown in figure 10. From the figure it is clear that in the elastic region stress is linearly proportional to strain. When the load exceeds a value corresponding to the yield strength, the specimen undergoes gross plastic deformation. It is permanently deformed if the load is released to zero. Different parameters derived from the tensile stress-strain curve are shown in table 2 .

(iii) Flexural stress-strain curve: Flexural stressstrain curve is also constructed from the load deformation measurements. Flexural stress is obtained by dividing the load by the original area of the cross section of the specimen. The strain used for the flexural stress-strain curve is the average linear strain, which is obtained by dividing the deflection of the gauge length of the specimen, by its original length. The flexural stress-strain curve has also the same shape as the load-deflection curve.
The plot of flexural stress vs strain for Saccharum cilliare fibre reinforced polymer composites is shown in figure 11. Different parameters derived from the tensile stressstrain curve are shown in table 3 .

In order to achieve good fibre reinforcement, interfacial strength between the fibre and matrix is the most essential factor. For a composite to be an effective load bearing system, the fibres and matrix must cooperate. This cooperation between the fibres and the matrix will not exist without the presence of the interface. The interfacial strength depends on the surface topology of the fibre. The interface acts as a 'binder' and transfers load between the matrix and the reinforcing fibres. The interfacial area plays a major role in determining the strength of composite material because each fibre forms an individual interface with the matrix. Interfacial bonding is a result of good wetting of the fibres by the RF matrix as well as the formation of a chemical bond between the fibre surface and the RF matrix. Hence the interface plays a key role in controlling the mechanical properties of a composite. It can be concluded that different degrees of reinforcement effects are achieved by the addition of natural fibres to RF matrix based polymer. This may be due to the different adhesion strengths between matrices and fibres. The adhesion is usually the strongest in polar polymers capable of forming hydrogen bonds with hydroxyl groups available on the fibre surface. The chemical bonding accounts for the adhesion between RF resin and cellulose of fibre. Still higher bond strength obtained for RF resin matrix is due to the possible reaction between the methylol groups of the resin with the hydroxyl group of cellulose.

Supplementary after a certain higher fibre loading a decrease in the mechanical properties of RF matrix based composites is observed. It has been observed that mechanical properties increase up to $30 \%$ fibre loading and then decreases. The mechanical strength of RF composites levels off at high fibre loading. This behaviour can be 
explained due to fibre-fibre contact at higher fibre loading. Hence lower results are obtained for $40 \%$ loading. Further when fibre-reinforced RF composites were subjected to a load, the fibres acted as carriers of load, and stress was transferred from the matrix along the fibres which resulted in composites with good mechanical properties. The uniform distribution of stress was dependent on the population and orientation of the fibres. At low levels of fibre loading, the orientation of fibres was poor, the fibres were not capable of transferring load to one another, and stress accumulated at certain points of the composite, which led to a lower mechanical properties. At $30 \%$ levels of loading the population of the fibres is just right for maximum orientation and the fibres actively participate in stress transfer and hence maximum results are obtained in case of this loading. As discussed, modulus showed a clear continuous increase up to $30 \%$ fibre load-

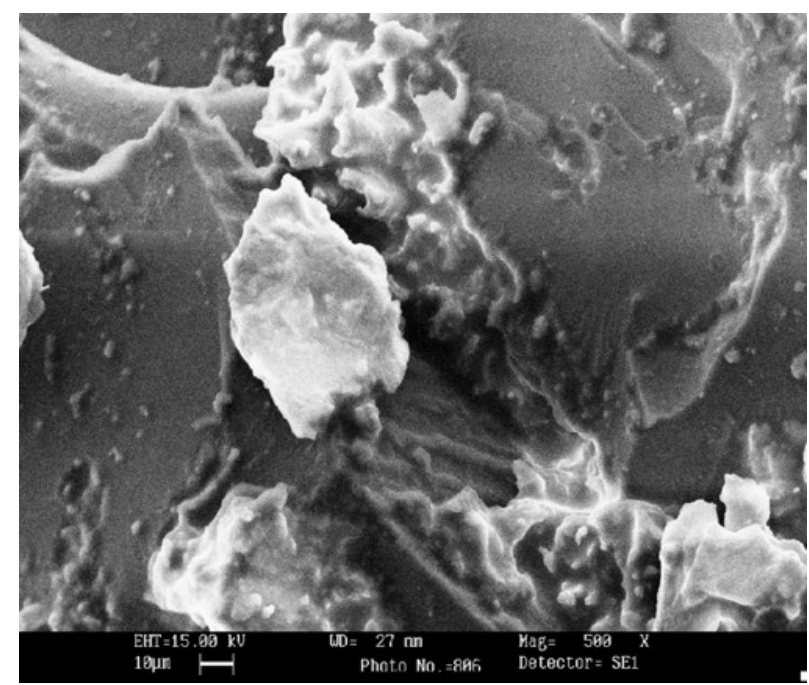

Figure 15. SEM of composite with $20 \%$ fibre loading.

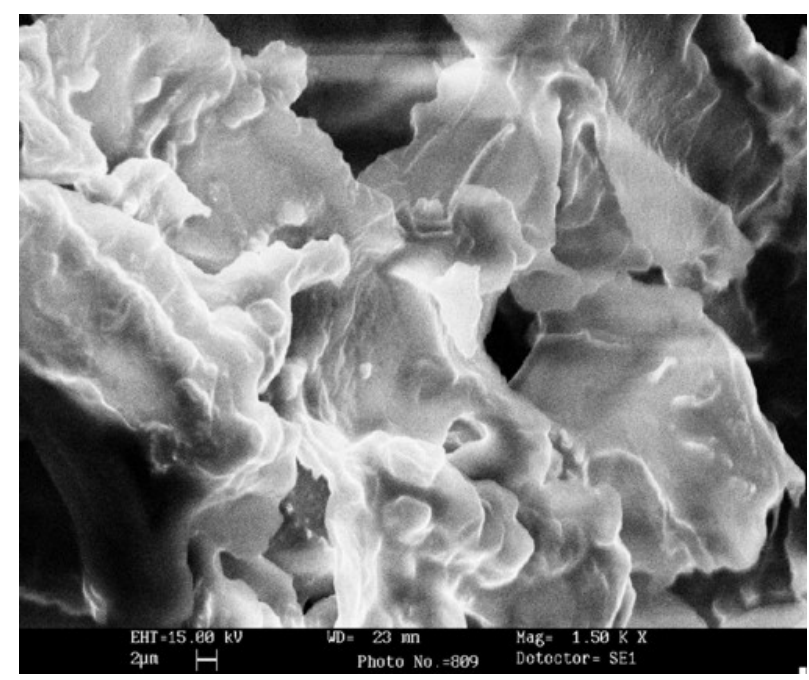

Figure 16. SEM of composite with $30 \%$ fibre loading. ing in the case of random orientation. At higher levels of fibre loading, the increased population of fibres led to agglomeration, and stress transfer was partially blocked resulting in lowering of mechanical properties after $30 \%$ loading.

These results suggest that Saccharum cilliare fibre has immense scope in the fabrication of natural fibre reinforced polymer composites having vast number of industrial applications. Further this can provide employment to a number of villagers.

\subsection{Morphological study of biocomposites}

Morphological results (figures 12-17) show that there is proper intimate mixing of fibre with the resin in the biocomposites thus synthesized. Morphological results evidently demonstrate that when polymer resin matrix is reinforced with different loadings of fibre, morphological changes take place depending upon the interfacial interaction between the varying loading of fibre and the resin matrix.

\subsection{Thermal behaviour of $R F$ resin and its composites}

Thermogravimetric analysis (TGA) of raw fibre, polymeric resin and biocomposite with $10 \%$ loading was studied as a function of $\%$ weight loss with the increase in temperature. In case of raw fibre, in the beginning of depolymerization, dehydration and glucosan formation took place between the temperature ranges of $26 \cdot 0^{\circ} \mathrm{C}$ and $195.0^{\circ} \mathrm{C}$ followed by the cleavage of $\mathrm{C}-\mathrm{H}, \mathrm{C}-\mathrm{C}$ and $\mathrm{C}-\mathrm{O}$ bonds. Initial decomposition (IDT) temperature is $212^{\circ} \mathrm{C}$ and final decomposition temperature is $471^{\circ} \mathrm{C}$. On the other hand, in case of polymeric resin (resorcinol formaldehyde), it is single stage decomposition and the initial

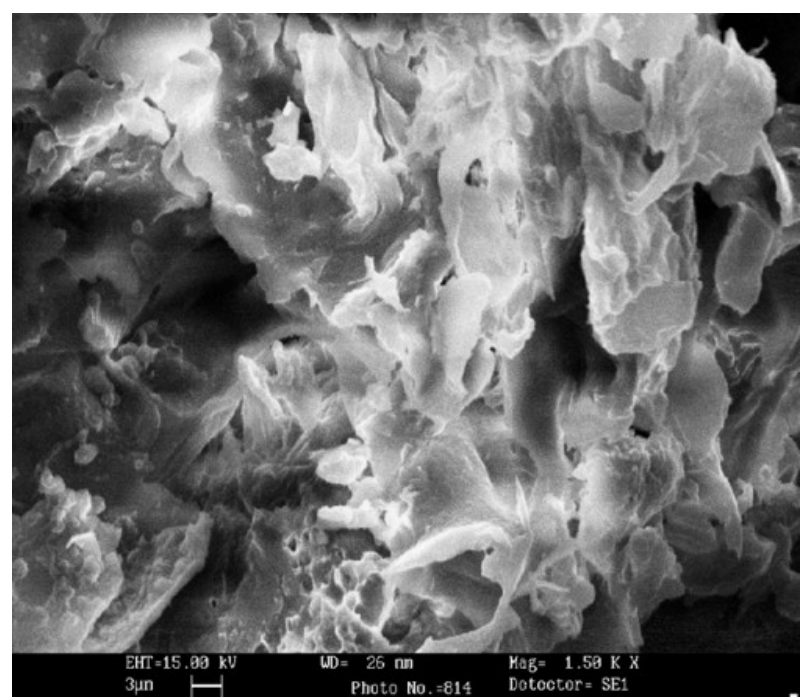

Figure 17. SEM of composite with $40 \%$ fibre loading 
Table 4. Thermogravimetric analysis of RF, SC and P-Rnf-UF composites.

\begin{tabular}{llccccc}
\hline Sr. No. & Sample code & IDT $\left({ }^{\circ} \mathrm{C}\right)$ & \% wt. loss & FDT $\left({ }^{\circ} \mathrm{C}\right)$ & \% wt. loss & Final residue $(\%)$ \\
\hline 1. & SC & 212 & 12.45 & 471 & 67.44 & $32 \cdot 66$ \\
2. & R-F resin & 299 & 22.64 & 990 & 51.78 & $48 \cdot 22$ \\
3. & P-Rnf-RF & 248 & 14.49 & 943 & $57 \cdot 37$ & $57 \cdot 48$ \\
\hline
\end{tabular}

Table 5. Differential thermal analysis of SC, RF and P-RnfUF composites.

\begin{tabular}{lll}
\hline Sr. No. & Sample code & \multicolumn{1}{c}{$\begin{array}{c}\text { Exothermic/endothermic peaks, } \\
{ }^{\circ} \mathrm{C}(\mu \mathrm{V})\end{array}$} \\
\hline 1. & SC & $326 \cdot 0(81) ; 430 \cdot 0(203)$ \\
2. & R-F resin & $65[-1 \cdot 0] ; 244[8 \cdot 0] ; 280[6 \cdot 0]$ \\
3. & P-Rnf-RF & $81[-10 \cdot 3]$ \\
\hline
\end{tabular}

decomposition temperature is $299 \cdot 0^{\circ} \mathrm{C}$, the final decomposition of the resin took place at $990 \cdot 0^{\circ} \mathrm{C}$. The degradation temperatures for natural fibre reinforced composites fall between the degradation temperatures for the matrix and the fibres. It has been observed that for biocomposites initial decomposition temperature is $248 \cdot 0^{\circ} \mathrm{C}$ and the final decomposition of the composite took place at $943.5^{\circ} \mathrm{C}$ which indicates that the presence of cellulose fibres does affect the degradation process. Similar behaviour is expected with rest of loading. The initial decomposition (IDT) temperature and final decomposition temperature (FDT) of fibre, resin and biocomposite are presented in table 4. This was consistent with results reported earlier (Nikki Sgriccia and Hawley 2007). These studies are further supported by differential thermal analysis (DTA) as shown in table 5 .

\section{Conclusions}

The mechanical properties of Saccharum cilliare fibre reinforced polymer composites have been investigated as a function of the chemical nature of matrix polymer and the content of the reinforcing material. Saccharum cilliare fibre has a potential ability to work as the reinforcement of polymer matrix. The mechanical properties of Saccharum cilliare fibre reinforced composites are higher than that of matrix polymer. High weight content of Saccharum cilliare fibre enables the Saccharum cilliare fibre composites to increase their strength in the most effective way, when the Saccharum cilliare fibre are modified into the 'particle shape'. The Saccharum cilliare fibres have the potential to be an ideal substitute fibre of synthetic fibres for synthesis of green composites. These composites can be future materials for the fabrication of eco-friendly materials.

\section{Acknowledgements}

We express our sincere thanks to Director, National Institute of Technology, Hamirpur, for providing basic laboratory facilities. Financial assistance from the University Grants Commission, New Delhi, through grant no. F.NO.-30-80/2004 (SR) is highly acknowledged.

\section{References}

Bhatnagar A and Sain M 2005 J. Reinf. Plast. Compos. 241259 Bledzki A K and Gassan J 1999 Prog. Polym. Sci. 24221

Bledzki A K, Reihmane S and Gassan J 1996 J. Appl. Polym. Sci. 591329

Bledzki A K, Reihmane S and Gassan J 1998 Polym. Plast. Technol. Eng. 37451

Chauhan G S, Kaur I, Misra B N, Singha A S and Kaith B S 1999 J. Polym. Mater. 16245

Chauhan G S, Kaur I, Misra B N, Singha A S and Kaith B S 2000a Polym. Degrad. \& Stab. 69261

Chauhan G S, Bhatt S S, Kaur I, Singha A S and Kaith B S 2000b J. Polym. Mater. 17363

Chauhan G S, Lal H, Singha A S and Kaith B S 2001 Indian J. Fibre \& Text. Res. 26302

De Debapriya and Adhikari Basudam 2004 Polym. Adv. Technol. 15708

Gassan J and Bledzki A K 1997 Compos. Part A-Appl. Sci. 28 1001

Gatenholm P, Bertilsson H and Mathiasson A 1993 J. Appl. Polym. Sci. 49197

Hagstrand P O and Oksman K 2001 Polym. Compos. 22568

Kaith B S, Singha A S, Susheel Kumar and Misra B N $2005 \mathrm{~J}$. Polym. Mater. 22425

Kaith B S, Singha A S and Susheel Kalia 2007 AUTEX Res. J. 7 119

Kaith B S, Singha A S, Sanjeev Kumar and Susheel Kalia 2008 Int. J. Polym. Mater. 5754

Nabi Saheb D and Jog J P 1999 Adv. Polym. Technol. 18351

Nakagiato A N and Yano H 2004 Appl. Phys. A-Mater. 78 547

Nikki Sgriccia and Hawley M C 2007 Compos. Sci. \& Technol. 671986

Panthapulakkal S, Zereshkian A and Sain M 2006 Bioresource Technol. 97265

Pizzi A and Cameron F A 1989 Wood adhesive chemistry and technology (New York: Marcel Dekker) 2

Singha A S and Shama Anjali 2007a Int. J. Chem. Sci. 51404

Singha A S and Thakur Vijay K 2007b Int. conf. on polymeric materials in power engineering (ICPMPE) (Bangalore) IVB8, pp 73 
Singha A S, Kaith B S and Sarwade B D 2002 Hung. J. Ind. Chem. VESZPREM 30289

Singha A S, Susheel Kumar and Kaith B S 2005 Int. J. Plast. Technol. 9427

Singha A S, Shama Anjali and Thakur Vijay K 2008a Bull. Mater. Sci. 317
Singha A S, Shama Anjali and Misra B N 2008b J. Polym. Mater. 2591

Velde van de K and Kiekens P 2001 Polym. Test. 20885

Velde van de K and Kiekens P 2003 Compos. Struct. 62443

Zárate C N, Aranguen M I and Reboredo M M $2000 \mathrm{~J}$. Appl. Polym. Sci. 771832 